PÔRTO MLA; PUIATTI M; FONTES PCR; CECON PR; ALVES JC. 2014. Índice SPAD para o diagnóstico do estado de nitrogênio na cultura do pepino japonês em ambiente protegido. Horticultura Brasileira 32: 292-296. DOI - http://dx.doi.org/10.1590/S0102-05362014000300009

\title{
Índice SPAD para o diagnóstico do estado de nitrogênio na cultura do pepino japonês em ambiente protegido
}

\author{
Mônica LA Pôrto ${ }^{1}$; Mário Puiatti²; Paulo CR Fontes ${ }^{2}$; Paulo R Cecon²; Jailson C Alves ${ }^{1}$ \\ 'IFAL, Campus Maragogi, Rod. AL 101 Norte s/n, 57955-000 Maragogi-AL; monicalporto@yahoo.com.br; jailson.alves@ifal.edu.br \\ ${ }^{2}$ UFV, Av. PH Holfs s/n, 36570-000 Viçosa-MG; mpuiatti@ufv.br; pacerefo@ufv.br; cecon@dpi.ufv.br;
}

\section{RESUMO}

O índice SPAD para o diagnóstico do estado de nitrogênio das culturas tem sido muito estudado nos últimos anos. O objetivo do trabalho foi avaliar o emprego do índice SPAD para o diagnóstico do estado de nitrogênio na cultura do pepino japonês (híbrido Taisho) em ambiente protegido. $\mathrm{O}$ experimento foi conduzido no delineamento em blocos casualizados, em esquema fatorial $2 \times 5$, constituído de duas fontes (sulfato de amônio e nitrato de amônio) e cinco doses ( 0 ; $75 ; 150 ; 300$ e $\left.600 \mathrm{~kg} \mathrm{ha}^{-1}\right)$ de nitrogênio, com quatro repetições. No início do florescimento, o teor de clorofila total, índice SPAD e teor de nitrogênio foram determinados na quarta folha completamente expandida, a partir do ápice das plantas. Não foram verificados efeitos significativos de fontes e da interação entre fontes e doses de nitrogênio sobre as características avaliadas. Entretanto, o teor de clorofila total, índice SPAD e teor de nitrogênio aumentaram de forma quadrática em função das doses de nitrogênio. Os níveis críticos foliares estimados de teor de clorofila total, índice SPAD e teor de nitrogênio responsáveis pela máxima produtividade da cultura do pepino japonês foram de $6,01 \mathrm{mg} \mathrm{g}^{-1}$ de matéria fresca, 52,33 unidades SPAD e 4,78 dag kg-1 de matéria seca, respectivamente. Houve correlação linear e positiva das características avaliadas entre si. O índice SPAD, determinado no início da fase reprodutiva, pode ser usado no diagnóstico do estado de nitrogênio da cultura do pepino japonês.

Palavras-chave: Cucumis sativus, clorofila, nutrição mineral.

\begin{abstract}
SPAD index for diagnosis of nitrogen status in the Japanese cucumber plants under protected cultivation

The employment of SPAD index for N status diagnosis of crops has been largely studied in recent years. Our objective was to evaluate the employment of SPAD index for nitrogen status diagnosis of Japanese cucumber plants (Taisho hybrid) under protected cultivation. The randomized block design was used, arranged in a $2 \times 5$ factorial design, with two nitrogen sources (ammonium sulfate and ammonium nitrate) and five nitrogen doses $\left(0 ; 75 ; 150 ; 300\right.$ and $\left.600 \mathrm{~kg} \mathrm{ha}^{-1}\right)$, with four replications. At the early flowering stage, total chlorophyll concentration, SPAD index and total nitrogen concentration in the fourth fully expanded leaf from the apex of Japanese cucumber plants were evaluated. No significant effects of nitrogen sources and of the interaction between nitrogen sources and nitrogen doses were found under the evaluated characteristics. However, total chlorophyll concentration, SPAD index and total nitrogen concentration in Japanese cucumber leaves increased following a quadratic model depending on the nitrogen doses. The estimated critical levels of total chlorophyll concentration, SPAD index and total nitrogen concentration on Japanese cucumber (Taisho hybrid) leaves responsible for the highest fruit yield were $6.01 \mathrm{mg} \mathrm{g}^{-1}$ of fresh matter,

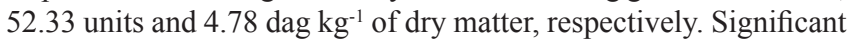
linear and positive correlation between the evaluated characteristics were observed. The SPAD index can be used for nitrogen status diagnosis of Japanese cucumber plants.
\end{abstract}

Keywords: Cucumis sativus, chlorophyll, mineral nutrition.

(Recebido para publicação em 26 de agosto de 2013; aceito em 12 de junho de 2014) (Received on August 26, 2013; accepted on June 12, 2014)

$\mathrm{N}$ o Brasil o pepino, principalmente do tipo japonês, é bastante cultivado em ambiente protegido. Com a utilização desse sistema de cultivo surgiram grandes benefícios, principalmente para os pequenos e médios produtores, pelo cultivo intensivo e alta produtividade (Canizares et al., 2004). Nesse sistema podem-se obter frutos de excelente qualidade comercial, com aumento significativo na lucratividade, em comparação com o cultivo em campo (Blanco \& Folegatti, 2002).

A escassez de informação consistente sobre a nutrição e adubação da cultura do pepino em condições de ambiente protegido, sobretudo a nitrogenada, constitui-se em grande entrave para a exploração dessa cultura, em função das peculiaridades observadas nesse sistema de cultivo, como menor perda de nutrientes por lixiviação e/ou por volatilização em comparação ao cultivo em campo aberto, além das cultivares utilizadas serem mais produtivas, respondendo a maiores quantidades de nutrientes (Blanco, 2006).

$\mathrm{O}$ nitrogênio ( $\mathrm{N}$ ) é um nutriente que influencia os processos envolvidos no crescimento e desenvolvimento das plantas, alterando a relação fonte-dreno e, consequentemente, a distribuição de assimilados entre órgãos vegetativos e reprodutivos (Queiroga et al., 2007). 
Assim, torna-se imprescindível indicar métodos eficientes de diagnóstico para avaliar o estado nutricional nitrogenado na cultura do pepino em ambiente protegido, de forma a contribuir para o manejo adequado deste nutriente. Nesse sentido, o emprego do índice SPAD para o diagnóstico do estado de $\mathrm{N}$ das culturas tem sido bastante estudado nos últimos anos (Fontes, 2011; Porto, 2011; Porto et al., 2011).

A determinação da cor verde da folha, possível de ser determinada por meio do medidor portátil SPAD-502, que proporciona leitura instantânea e de maneira não destrutiva, destaca-se recentemente como alternativa para avaliar o estado de $\mathrm{N}$ da planta em tempo real pelo fato de haver correlação significativa entre a intensidade da cor verde com o teor de clorofila e com a concentração de $\mathrm{N}$ na folha (Gil et al., 2002; Fontes, 2011; Pôrto et al., 2011).

O medidor portátil SPAD-502 avalia, quantitativamente, a intensidade do verde da folha, medindo as transmissões de luz a $650 \mathrm{~nm}$, onde ocorre absorção de luz pela molécula de clorofila, e a 940 $\mathrm{nm}$, onde não ocorre absorção (Gil et al., 2002; Ferreira et al., 2006). Com estes dois valores, o equipamento calcula um número ou índice SPAD que, normalmente, é altamente correlacionado com o teor de clorofila da folha e pode identificar deficiência, toxidez e concentração adequada de N. (Gil et al., 2002).

Índices SPAD obtidos em folhas de diversas espécies apresentaram correlação positiva com a suficiência de $\mathrm{N}$, podendo este ser considerado um índice apropriado para avaliar o estado de $\mathrm{N}$ das culturas (Gil et al., 2002; Fontes, 2011; Pôrto et al., 2011). O medidor portátil SPAD-502 tem sido utilizado com sucesso para diagnosticar o estado de N em batata (Gil et al., 2002; Silva et al., 2009; Coelho et al., 2010), pimentão (Madeira et al., 2003), tomate (Ferreira et al., 2006; Güler \& Büyük, 2007), dentre outras culturas. Entretanto, trabalhos acerca do emprego do índice SPAD para diagnóstico do estado de $\mathrm{N}$ na cultura do pepino japonês em condições de ambiente protegido são bastante escassos na literatura, sobretudo em condições brasileiras.

O objetivo deste trabalho foi avaliar o uso do índice SPAD para o diagnóstico do estado de $\mathrm{N}$ na cultura do pepino japonês em ambiente protegido.

\section{MATERIAL E MÉTODOS}

O experimento foi conduzido em área experimental da Universidade Federal de Viçosa, em Viçosa-MG. No preenchimento dos canteiros de cultivo foi empregado solo coletado do Horizonte B de um Argissolo Vermelho-Amarelo Câmbico, o qual apresentava textura muito argilosa e as seguintes características químicas: $\mathrm{pH}$ em $\mathrm{H}_{2} \mathrm{O}=5,5 ; \mathrm{P}=2,6 \mathrm{mg}$ $\mathrm{dm}^{-3} ; \mathrm{K}^{+}=24,0 \mathrm{mg} \mathrm{dm}{ }^{-3} ; \mathrm{Ca}^{2+}=0,2 \mathrm{cmol}_{\mathrm{c}}$ $\mathrm{dm}^{-3} ; \mathrm{Mg}^{2+}=0,1 \mathrm{cmol}_{\mathrm{c}} \mathrm{dm}^{-3} ; \mathrm{S}^{-\mathrm{SO}_{4}{ }^{2-}=}$ $49,4 \mathrm{mg} \mathrm{dm}^{-3} ; \mathrm{Al}^{3+}=0,4 \mathrm{cmol}_{\mathrm{c}} \mathrm{dm}^{-3} ; \mathrm{H}+$ $\mathrm{Al}=3,80 \mathrm{cmol} \mathrm{dm}^{-3}$; e matéria orgânica $=0,7 \mathrm{dag} \mathrm{kg}^{-1}$.

Durante o período de condução do experimento, os valores médios de temperatura máxima, mínima e umidade relativa diária no interior da estufa foram: $33,1^{\circ} \mathrm{C}, 17,1^{\circ} \mathrm{C}$ e $65,5 \%$ respectivamente, valores estes dentro da faixa adequada para a cultura do pepino (Fontes \& Puiatti, 2005).

As mudas de pepino japonês híbrido Taisho (ginóico partenocárpico) foram produzidas em bandejas de isopor (128 células), utilizando-se substrato comercial Plantmax ${ }^{\circledR}$. A semeadura foi realizada em 03/09/2010 e as mudas transplantadas para o local de cultivo em 21/09/2010, quando apresentaram duas folhas definitivas.

O experimento foi constituído de 10 tratamentos, distribuídos em esquema fatorial $2 \times 5$, correspondentes a duas fontes (sulfato de amônio e nitrato de amônio) e cinco doses $(0 ; 75 ; 150$; 300 e $600 \mathrm{~kg} \mathrm{ha}^{-1}$ ) de N. Utilizou-se o delineamento experimental em blocos casualizados, com quatro repetições.

A calagem e a adubação com fósforo, potássio e micronutrientes foram determinadas mediante análise química do solo e sugestões de recomendação para a cultura no estado de Minas Gerais (Filgueira et al., 1999). A calagem constou da aplicação de 4,8 t ha-1 de calcário dolomítico, realizada 60 dias antes do transplante das mudas. Foram aplicados $1.500 \mathrm{~kg} \mathrm{ha}^{-1}$ de superfosfato simples, $200 \mathrm{~kg} \mathrm{ha}^{-1}$ de cloreto de potássio, 15 $\mathrm{kg} \mathrm{ha}^{-1}$ de sulfato de zinco, $10 \mathrm{~kg} \mathrm{ha}^{-1}$ de bórax, $10 \mathrm{~kg} \mathrm{ha}^{-1}$ de sulfato de cobre e $0,5 \mathrm{~kg} \mathrm{ha}^{-1}$ de molibdato de amônio.

O sulfato de amônio foi empregado como uma das fontes de $\mathrm{N}$ em razão de essa ser a principal fonte de adubo nitrogenado empregada na cultura. Além disso, o solo apresentava disponibilidade alta de enxofre (Alvarez et al., 1999), além de ter sido veiculado, aproximadamente, $150 \mathrm{~kg} \mathrm{ha}^{-1}$ desse nutriente como elemento acompanhante do superfosfato simples, sulfato de zinco e sulfato de cobre. Portanto, essas condições são suficientes para eliminar possíveis interferências do $\mathrm{S}$ adicionado mediante a aplicação das doses crescentes de $\mathrm{N}$ na forma de sulfato de amônio.

Cerca de 10 dias antes do transplante das mudas foram aplicados o total recomendado de micronutrientes e do fósforo, $30 \%$ do nitrogênio e $40 \%$ do potássio. $\mathrm{O}$ restante do nitrogênio e do potássio foi aplicado em duas coberturas, sendo a primeira aos 15 dias após o transplante e a segunda 25 dias após a primeira (Fontes \& Puiatti, 2005).

$\mathrm{O}$ pepino japonês foi cultivado em estufa tipo capela, com dimensões de 10x12 m e pé-direito de $2,5 \mathrm{~m}$, com cortinas laterais retráteis, e coberta com filme plástico de 150 micra aditivado contra UV. $\mathrm{O}$ plantio foi realizado em canteiros com dimensões de 1,0 m de largura, 10,0 m de comprimento e 0,25 $\mathrm{m}$ de profundidade. Em cada canteiro, foram desprezados 0,5 m de cada extremidade (bordadura), sendo constituídas cinco parcelas experimentais com 1,8 m de comprimento. Na parcela, foram cultivadas 12 plantas, dispostas em duas fileiras com seis plantas, no espaçamento de $1 \times 0,30 \mathrm{~m}$. A área útil da parcela foi constituída de oito plantas (quatro plantas centrais de cada fileira).

As plantas foram mantidas verticalmente, com uso de fitilhos, e em haste única. Foi realizada a desbrota das ramas laterais ao longo do ciclo e a retirada do meristema apical da planta (capação) ao atingir a altura de aproximadamente 1,8 m do solo. Durante a condução da cultura foram realizadas irrigações por gotejamento sempre que necessário e com volume semelhante e suficiente para manter a umidade do solo próximo da capacidade de campo. As pulverizações, para controle de pragas e doenças foram 
realizadas com produtos registrados para a cultura, seguindo as orientações dos produtos quanto as dosagens e intervalos de aplicação recomendados.

Para determinação do índice SPAD na cultura do pepino japonês, adotou-se o critério que vem sendo empregado para outras cucurbitáceas, que é a realização da leitura na folha mais jovem completamente expandida, que em geral é a terceira ou quarta folha a partir do ápice (Swiader \& Moore, 2002; Güler \& Büyük, 2007; Porto et al., 2011). Neste trabalho, padronizou-se o emprego da leitura na quarta folha a partir do ápice para a determinação do índice SPAD.

No início do florescimento, 24 dias após o transplante das mudas, determinou-se o índice SPAD entre as 7 e $9 \mathrm{~h}$, utilizando o medidor portátil de clorofila SPAD-502 (Minolta Camera Co. Ltd.). Foram realizadas cinco medições do índice SPAD na porção mediana do limbo foliar de cada planta da área útil, totalizando 40 medições por parcela, em cada tratamento, sendo utilizada a média para representar os tratamentos.

Imediatamente após o término das leituras, as folhas foram destacadas de cada planta, acondicionadas em sacos plásticos e, no laboratório, mantidas sob refrigeração. Em seguida, tomou-se uma amostra composta de $0,1 \mathrm{~g}$ de matéria fresca, a qual foi macerada em acetona a $80 \%$, na presença de $\mathrm{CaCO}_{3}$. Os extratos obtidos foram filtrados através de papel-filtro e coletados em balões volumétricos de $50 \mathrm{~mL}$, completando-se o volume ao final da filtragem. A densidade ótica dos filtrados foi lida em espectrofotômetro a 645 e 663 nm, utilizando cubetas de quartzo. A partir dessas leituras, determinou-se a concentração de clorofila nas soluções de leitura, de acordo com o proposto por Arnon (1949). Os valores das concentrações de clorofila total no limbo foliar foram expressos em base de massa ( $\mathrm{mg} \mathrm{g}^{-1} \mathrm{de}$ matéria fresca).

Posteriormente, o restante das folhas foi acondicionado em sacos de papel, secos em estufa de circulação forçada de ar a $75^{\circ} \mathrm{C}$, até atingirem peso constante, sendo em seguida pesados, passados por moinho tipo Willey com peneira de 20 mesh e armazenados. Nas matérias secas das folhas, após a extração com água em banho-maria a $45^{\circ} \mathrm{C}$, durante uma hora, determinaram-se as concentrações de $\mathrm{N}-\mathrm{NO}_{3}{ }^{-}$por colorimetria, em espectrofotômetro a $410 \mathrm{~nm}$ (Cataldo et al., 1975). Determinaram-se, ainda, após digestão sulfúrica, os teores de N-orgânico na matéria seca das folhas por meio do reagente de Nessler (Jackson, 1982) calculando-se, posteriormente, os valores de $\mathrm{N}$ total a partir da soma dos teores de $\mathrm{N}^{-} \mathrm{NO}_{3}^{-}$e de $\mathrm{N}$ orgânico.

A partir da dose de $406 \mathrm{~kg} \mathrm{ha}^{-1}$ de $\mathrm{N}$, dose responsável pela máxima produtividade de frutos de pepino japonês (76,40 t ha' ${ }^{-1}$ ) (Pôrto, 2011), foram calculados os valores dos níveis críticos do teor de clorofila total, índice SPAD e teor de $\mathrm{N}$ nas folhas das plantas, seguindo método descrito em Fontes (2011).

Os resultados obtidos foram submetidos à análise de variância, com desdobramento do efeito das doses de $\mathrm{N}$ em regressão, considerando-se até $\mathrm{p}<0,05$. A escolha do modelo, além da significância do ajuste do $\left(\mathrm{R}^{2}\right)$, levou em consideração a explicação biológica do fenômeno em estudo. Também foi realizada análise de correlação de Pearson entre as características analisadas. As análises estatísticas foram realizadas utilizando o software SAEG, v. 9.1 (SAEG, 2007).

\section{RESULTADOS E DISCUSSÃO}

Não foram verificados efeitos significativos de fontes e da interação entre fontes e doses de N sobre as características avaliadas. Este fato demonstra que ambas as fontes de $\mathrm{N}$ empregadas (sulfato de amônio e nitrato de amônio) apresentaram influência similar sobre o teor de clorofila total, índice SPAD e teor de $\mathrm{N}$ total nas folhas do pepino japonês.

Entretanto, o teor de clorofila total, o índice SPAD e o teor de $\mathrm{N}$ total nas folhas do pepino japonês foram significativamente afetados $(\mathrm{p}<0,01)$ pelas doses de N (Figuras 1; 2 e 3).

O teor de clorofila total e índice SPAD apresentaram comportamento bastante similar, com resposta quadrática em função da elevação das doses de N (Figuras 1 e 2). Para essas características foram obtidos máximos valores estimados de $6,02 \mathrm{mg} \mathrm{g}^{-1}$ de matéria fresca e de 52,54 unidades SPAD, respectivamente, nas doses 417 e $468 \mathrm{~kg} \mathrm{ha}^{-1}$ de N. Esses

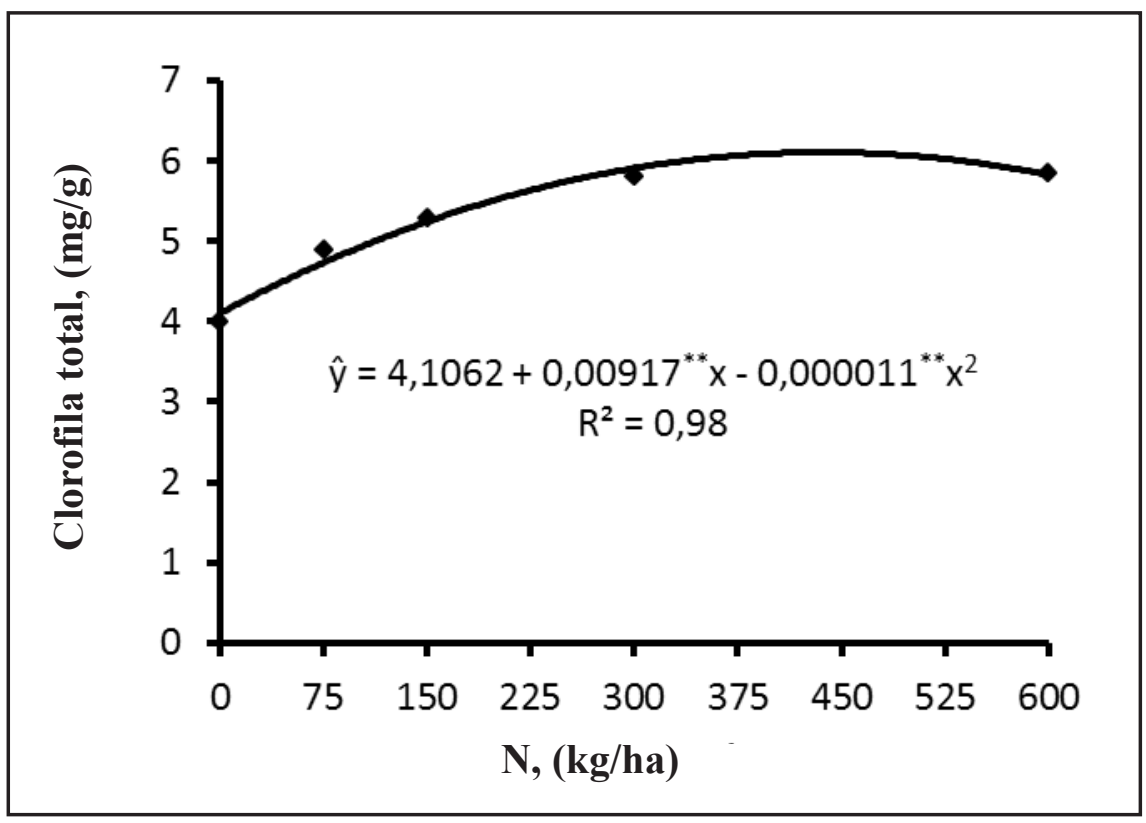

Figura 1. Teor de clorofila total na matéria fresca da folha de pepino japonês em ambiente protegido em função da adubação nitrogenada (total chlorophyll concentration in the fresh matter of japanese cucumber leaf under protected cultivation depending on the nitrogen fertilization). Viçosa, UFV, 2010.

${ }^{* *}$ Significativo a $1 \%$ de probabilidade, pelo teste $\mathrm{t}$ (significant at $1 \%, \mathrm{t}$ test). 


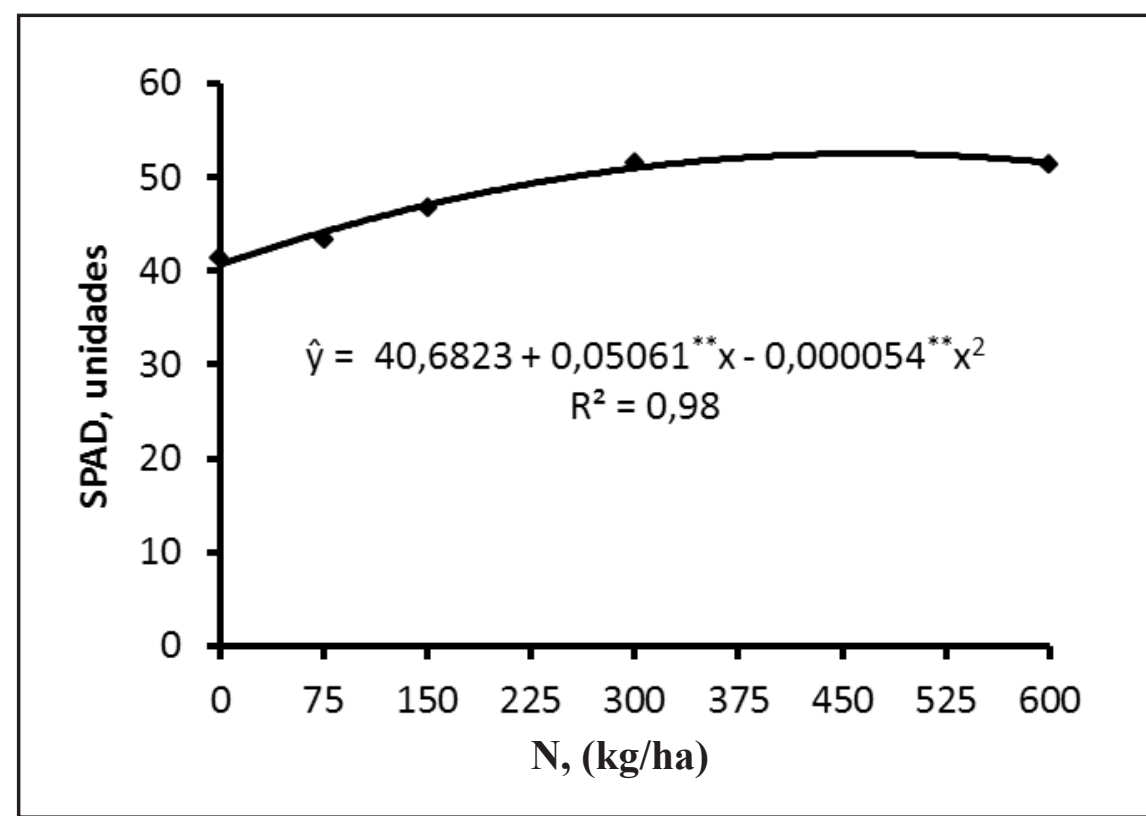

Figura 2. Índice SPAD em folha de pepino japonês em ambiente protegido em função da adubação nitrogenada (SPAD index on japanese cucumber leaf under protected cultivation depending on the nitrogen fertilization). Viçosa, UFV, 2010.

${ }^{* *}$ Significativo a $1 \%$ de probabilidade, pelo teste $\mathrm{t}$ (significant at $1 \%, \mathrm{t}$ test).

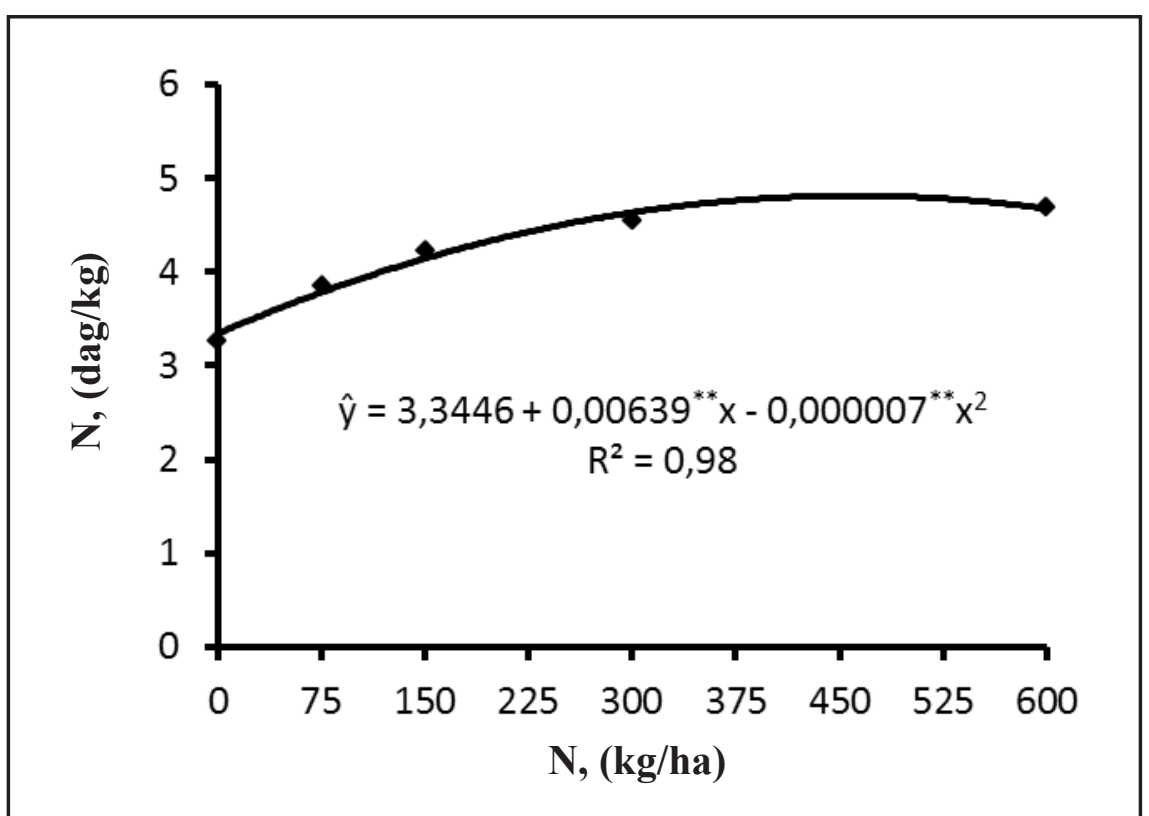

Figura 3. Teor de $\mathrm{N}$ total na matéria seca da folha de pepino japonês em função da adubação nitrogenada em ambiente protegido (total $\mathrm{N}$ concentration in the dry matter of japanese cucumber leaf under protected cultivation depending on the nitrogen fertilization). Viçosa, UFV, 2010.

${ }^{* *}$ Significativo a $1 \%$ de probabilidade, pelo teste $\mathrm{t}$ (significant at $1 \%, \mathrm{t}$ test).

resultados corroboram aos obtidos por outros autores para as culturas da abóbora (Swiader \& Moore, 2002), abobrinha (Pôrto et al., 2011), batata (Gil et al., 2002), tomate (Ferreira et al., 2006; Güler \& Büyük, 2007) dentre outras culturas, onde também foram consta- plantas, até determinado limite, proporciona incremento no teor de clorofila e intensidade de cor verde nas folhas da planta (Gil et al., 2002; Fontes, 2011; Pôrto et al., 2011).

Com o emprego da dose de $406 \mathrm{~kg}$ $\mathrm{ha}^{-1} \mathrm{de} \mathrm{N}$, dose responsável pela máxima produtividade de frutos de pepino japonês (Pôrto, 2011), os valores dos níveis críticos estimados do teor de clorofila total e índice SPAD foram $6,01 \mathrm{mg} \mathrm{g}^{-1}$ de massa de matéria fresca e de 52,33 unidades SPAD, respectivamente. O nível crítico de índice SPAD obtido no presente trabalho se encontra acima do verificado por Güler \& Büyük (2007) para a cultura do pepino japonês (cv. Seyhan) em ambiente protegido submetido a quatro doses de $\mathrm{N}(0,100,150 \mathrm{e}$ $200 \mathrm{mg} \mathrm{L}^{-1}$ ), aplicado via fertirrigação, em dois anos de cultivo (2000 e 2001), que encontraram valores de nível crítico (associado com a máxima produtividade) de 44,93 unidades SPAD. Entretanto, encontra-se bem próximo dos níveis críticos de índice SPAD (associados com a máxima produtividade) preconizado para outras cucurbitáceas, como abobrinha $(55,62$ unidades SPAD) (determinado na quarta folha recentemente expandida, a partir do ápice, das plantas, no início do florescimento) (Pôrto et al., 2011) e abóbora (56,7 a 59,0 unidades SPAD) (determinado em folhas novas recentemente expandidas, durante a fase de antese, em cultivos de sequeiro e sob irrigação, respectivamente) (Swiader \& Moore, 2002).

$\mathrm{O}$ teor de $\mathrm{N}$ total na matéria seca das folhas do pepino japonês também apresentou resposta quadrática em função do incremento das doses de N (Figura 3), onde o máximo teor de $\mathrm{N}$ total estimado nas folhas de pepino japonês $(4,80 \mathrm{dag}$ $\mathrm{kg}^{-1}$ de matéria seca) foi obtido na dose $456 \mathrm{~kg} \mathrm{ha}^{-1} \mathrm{de} \mathrm{N}$. Com o emprego da dose responsável pela máxima produtividade de frutos de pepino japonês (406 kg ha $^{-1}$ de N) (Pôrto, 2011), o nível crítico estimado do teor de $\mathrm{N}$ foliar foi 4,78 dag $\mathrm{kg}^{-1}$ na matéria seca. Esse teor de $\mathrm{N}$ encontra-se dentro da faixa considerada suficiente para a cultura do pepino que seria de 4,5 a 6,0 dag $\mathrm{kg}^{-1}$ na matéria seca (Trani \& Raij, 1996), indicando que as plantas apresentavam-se adequadamente nutridas quanto a esse nutriente. 
Foram verificadas elevadas correlações entre as características estudadas, ou seja: $r=0,94(\mathrm{p}<0,001)$ entre índice SPAD e teor de clorofila total; $r=0,94$ $(\mathrm{p}<0,001)$ entre índice SPAD e teor de $\mathrm{N}$ total, e $\mathrm{r}=0,95(\mathrm{p}<0,001)$ entre teor de clorofila total e teor de $\mathrm{N}$ total. Esses resultados indicam a possibilidade de utilização do medidor portátil SPAD502 na avaliação indireta do teor de clorofila total e na caracterização do estado de $\mathrm{N}$ na cultura do pepino japonês, apresentando inúmeras vantagens. Dentre as vantagens estão a rapidez, simplicidade e, principalmente, a possibilidade de avaliação não destrutiva do tecido foliar, podendo ser realizada diretamente a campo (Amarante et al., 2008). Para tal fim, foram ajustadas as seguintes equações:

Teor de clorofila total ( $\mathrm{mg} \mathrm{g}^{-1}$ de matéria fresca $)=-2,2167+0,1574^{* *}$ SPAD

Teor de $\mathrm{N}$ total (dag $\mathrm{kg}^{-1}$ de matéria seca) $=-1,3895+0,1174^{* *}$ SPAD

O conteúdo de clorofila, estimado com o medidor portátil SPAD-502, correlaciona-se com a concentração de $\mathrm{N}$ na planta e também com o rendimento de diversas espécies (Gil et al., 2002; Fontes, 2011; Pôrto et al., 2011), podendo ser usado como ferramenta auxiliar para caracterizar de forma indireta a necessidade de adubação nitrogenada. Em hortaliças, o índice SPAD tem sido utilizado com sucesso para diagnosticar o estado nitrogenado em alho (Backes et al., 2008), batata (Gil et al., 2002) tomate (Ferreira et al., 2006) e pimentão (Madeira et al., 2003), dentre outras.

Os resultados deste trabalho corroboram com os obtidos por Güler \& Büyük (2007), em experimento realizado com a cultura do pepino japonês (cv. Seyhan) em ambiente protegido, em dois anos de cultivo (2000 e 2001), submetido a quatro doses de $\mathrm{N}\left(0,100,150\right.$ e $\left.200 \mathrm{mg} \mathrm{L}^{-1}\right)$, aplicado via fertirrigação. Esses autores também verificaram correlação linear positiva e significativa entre os valores do índice SPAD e os teores de $\mathrm{N}$ total $(\mathrm{r}=0,786$, $\mathrm{p}<0,001$ ), indicando a possibilidade de utilização do índice SPAD na caracterização do estado de $\mathrm{N}$ dessa cultura. Resultados relevantes também foram obtidos para outras cucurbitáceas, como abobrinha (Pôrto et al., 2011) e abóbora (Swiader \& Moore, 2002), onde também foram constatadas elevadas correlações entre índice SPAD e teor de $\mathrm{N}$ nas folhas das plantas. Todavia, como o equipamento fornece uma leitura em unidades arbitrárias (leitura SPAD de conteúdo de clorofila, na faixa de 0 a 99,9), recomenda-se que o mesmo seja calibrado com as extrações de clorofilas da cultura de interesse (Amarante, 2008; Pôrto et al., 2011), como realizado no presente estudo.

Os resultados deste trabalho indicam que o índice SPAD, determinado no início da fase reprodutiva, pode ser usado com eficiência para diagnóstico do estado de $\mathrm{N}$ da cultura do pepino japonês em ambiente protegido, a exemplo do que vem sendo observado para outras culturas.

\section{AGRADECIMENTOS}

Ao CNPq, pela concessão da bolsa de estudos de DS ao primeiro autor e de produtividade em pesquisa para $\mathrm{o}$ segundo, terceiro e quarto autores. À FAPEMIG, pelo apoio para realização da pesquisa.

\section{REFERÊNCIAS}

ALVAREZ VVH; NOVAIS RF; BARROS NF; CANTARUTTI RB; LOPES AS. 1999. Interpretação dos resultados das análises de solos. In: RIBEIRO AC; GUIMARES H; ALVAREZ VVH (eds). Recomendações para uso de corretivos e fertilizantes em Minas Gerais - $5^{a}$ Aproximação. Viçosa: CFSEMG. p. 25-32.

AMARANTE CVT; BISOGNIN DA; STEFFENS CA; ZANARDI OZ; ALVES EO. 2008. Quantificação não destrutiva de clorofilas em folhas através de método colorimétrico. Horticultura Brasileira 26: 471-475.

ARNON DI. 1949. Cooper enzymes in isolated chloroplasts. Polyphenoloxydase in Beta vulgaris. Plant Physiology 24: 1-15.

BACKES C; LIMA CP; GODOY LJG; BÔAS LRV; IMAIZUMI I. 2008. Coloração verde nas folhas da cultura do alho vernalizado em resposta à adubação nitrogenada. Bragantia 67: 491-498.

BLANCO FF. 2006. Fertirrigação na cultura do pepino. In: BOARETTO AE; VILLAS BÔAS RL; SOUSA VF; PARRA IRV (eds). Fertirrigação: teoria e prática. Piracicaba: Os autores. p.305-303.

BLANCO FF; FOLEGATTI MV. 2002. Manejo da água e nutrientes para o pepino em ambiente protegido sob fertirrigação. Revista Brasileira de Engenharia Agrícola e Ambiental 6: 251255.

CANIZARES KAL; RODRIGUES JD; GOTO R. 2004. Crescimento e índices de troca gasosa em plantas de pepino irrigadas com água enriquecida com $\mathrm{CO}_{2}$. Horticultura Brasileira 22: 706-711.

CATALDO DA; HAROON M; SCHRADER LE; YOUNES VL. 1975. Rapid colorimetric determination of nitrate in plant tissue by nitration of salicylic acid. Communications in Soil Science and Plant Analysis 6: 71-80.

COELHO FS; FONTES PCR; PUIATTI M; NEVES JCL; SILVA MCC. 2010. Dose de nitrogênio associada à produtividade de batata e índices do estado de nitrogênio na folha. Revista Brasileira Ciência do Solo 34: 1175-1183.

FERREIRA MMM; FERREIRA GB; FONTES PCR; DANTAS JP. 2006. Índice SPAD e teor de clorofila no limbo foliar do tomateiro em função de doses de nitrogênio e da adubação orgânica, em duas épocas de cultivo. Revista Ceres 53: 83-92.

FILGUEIRA FAR; AVELAR FILHO JA; CARRIJO IV. 1999. Pepino. In: RIBEIRO AC; GUIMARES H; ALVAREZ VVH (eds). Recomendações para uso de corretivos e fertilizantes em Minas Gerais - $5^{a}$ Aproximação. Viçosa: CFSEMG. p.200.

FONTES PCR. 2011. Nutrição mineral de plantas: avaliação e diagnose. Viçosa: O autor. 296p.

FONTES PCR; PUIATTI M. 2005. Cultura do pepino. In: FONTES PCR (ed). Olericultura: teoria e prática. Viçosa: DFT - Setor de Olericultura/UFV. p.439-455.

GIL PT; FONTES PCR; CECON PR; FERREIRA FA. 2002. Índice SPAD para o diagnóstico do estado de nitrogênio e para o prognóstico da produtividade de batata. Horticultura Brasileira 20: 611-615.

GÜLER S; BÜYÜK G. 2007. Relationships among chlorophyll-meter reading value, leaf $\mathrm{N}$ and yield of cucumber and tomatoes. Acta Horticulturae 729: 307-311.

JACKSON ML. 1982. Análisis quimico de suelos. Barcelona: Ediciones Omega S.A. 662p.

MADEIRA AC; FERREIRA A; VARENNES A; VIEIRA MI. 2003. SPAD meter versus tristimulus colorimeter to estimate chlorophyll content and leaf color in sweet pepper. Communications in Soil Science and Plant Analysis 34: 2461-2470.

PÔRTO MLA. 2011. Adubação nitrogenada e diagnóstico do estado de nitrogênio nas culturas de abobrinha, abóbora tipo "Tetsukabuto" e pepino. Viçosa: UFV. (Tese doutorado).

PÔRTO ML; PUIATTI M; FONTES PCR; CECON PR; ALVES JC; ARRUDA JA. 2011. Índice SPAD para o diagnóstico do estado de nitrogênio na cultura da abobrinha. Horticultura Brasileira 29: 311-315.

QUEIROGA RCF; PUIATTI M; FONTES PCR; CECON PR; FINGER FL. 2007. Influência de doses de nitrogênio na produtividade e qualidade do melão Cantalupensis sob ambiente protegido. Horticultura Brasileira 25: 550-556.

SAEG. Sistema para Análises Estatísticas. 2007. Versão 9.1. Viçosa: Fundação Arthur Bernardes.

SILVA MCC; FONTES PCR; MIRANDA GV. 2009. Índice SPAD e produção de batata, em duas épocas de plantio, em função de doses de nitrogênio. Horticultura Brasileira 27: 17-22.

SWIADER JM; MOORE A. 2002. SPADchlorophyll response to nitrogen fertilization and evaluation of nitrogen status in dryland and irrigated pumpkins. Journal of Plant Nutrition 25: 1089-1100.

TRANI PE; RAIJ BV. 1996. Hortaliças. In: RAIJ BV; CANTARELLA H; QUAGGIO JA; FURLANI AMC (eds). Recomendações de adubação e calagem para o Estado de São Paulo. 2.ed. Campinas: IAC. p. 157-185. (Boletim Técnico, 100). 